\title{
Highly Sensitive Electrocatalytic Determination of Formaldehyde Using a Ni/Ionic Liquid Modified Carbon Nanotube Paste Electrode
}

\author{
Ebrahim Zarei ${ }^{*}$, Mohammad Reza Jamali², Farideh Ahmadi ${ }^{2}$ \\ ${ }^{1}$ Department of Basic Sciences, Farhangian University, Tehran, Iran \\ ${ }^{2}$ Department of Chemistry, Payame Noor University, Tehran, Iran
}

Received: $11^{\text {st }}$ March 2018; Revised: $20^{\text {th }}$ July 2018; Accepted: $28^{\text {th }}$ July 2018;

Available online: $14^{\text {th }}$ November 2018; Published regularly: December 2018

\begin{abstract}
In this study, ionic liquid 1-hexyl-3-methylimidazolium hexafluorophosphate was applied as additives to fabricate a novel ionic liquid/carbon nanotube paste electrode (IL/CNPE). This electrode was characterized by electrochemical impedance spectroscopy and cyclic voltammetry. Results showed that the electron transfer rate and reversibility of the electrode were increased by the ionic liquid. The morphology of prepared IL/CNPE was studied by scanning electron microscopy. Nickel/ionic liquid modified carbon nanotube paste electrode (Ni/IL/CNPE) was also constructed by immersion of the IL/CNPE in nickel sulfate solution. Ionic liquid showed significant effect on the accumulation of nickel species on the surface of the electrode. Also, the values of electron transfer coefficient, charge-transfer rate constant and electrode surface coverage for $\mathrm{Ni}(\mathrm{II}) / \mathrm{Ni}$ (III) redox couple of the Ni/IL/CNPE were found to be 0.32 and $2.37 \times 10^{-1} \mathrm{~s}^{-1}$ and $2.74 \times 10^{-8} \mathrm{~mol}^{-\mathrm{cm}^{-2}}$, respectively. The Ni/IL/CNPE was applied successfully to highly efficient electrocatalytic oxidation of formaldehyde in alkaline medium. The effects of various factors on the efficiency of electrocatalytic oxidation of formaldehyde were optimized. Under the optimized condition, cyclic voltammetry of formaldehyde at the modified electrode exhibited two linear dynamic ranges in the concentration ranges of $7.00 \times 10^{-6}$ to $9.60 \times 10^{-5} \mathrm{~mol}^{-\mathrm{L}^{-1}}$ and $9.60 \times 10^{-5}$ to $32.00 \times 10^{-3}$

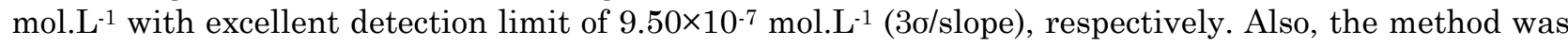
successfully applied for formaldehyde measurement in real sample. Copyright (C) 2018 BCREC Group. All rights reserved
\end{abstract}

Keywords: Nickel; Ionic Liquid; Carbon Nanotube Paste Electrode; Electrocatalytic Oxidation; Formaldehyde

How to Cite: Zarei, E., Jamali, M.R., Ahmadi, F. (2018). Highly Sensitive Electrocatalytic Determination of Formaldehyde Using a Ni/Ionic Liquid Modified Carbon Nanotube Paste Electrode. Bulletin of Chemical Reaction Engineering \& Catalysis, 13 (3): 529-542 (doi:10.9767/bcrec.13.3.2341.529-542)

Permalink/DOI: https://doi.org/10.9767/bcrec.13.3.2341.529-542

\section{Introduction}

Formaldehyde is one of the toxic pollutants (as a carcinogen) [1]. Also, this material was ap-

\footnotetext{
* Corresponding Author.

E-mail: e.zarei@cfu.ac.ir (E. Zarei)

Telp: +98-11-33833114, Fax: +98-11-33833114
}

plied as an extremely important industrial raw material for the production of phenol-, urea-, and melamine-formaldehyde resins and manufacturing of building plates, plywood, and lacquer materials $[2,3]$. Formaldehyde is also used in chemical synthesis as an intermediate for the production of consumer goods as detergents, soaps, shampoos, and as a sterilizing agent in 
pharmacology and medicine. On the other hand, formaldehyde is a natural metabolite of living organisms. It can be found in fruits, vegetables, flesh [4] and biological fluids of human origin [2]. Therefore, simple and sensitive methods for determination of formaldehyde are needed for specific biotechnological processes, environmental control, medicine and even for drinking water and food analysis. Compared with spectral and chromatographic analysis, electroanalytical method has been considered as a good alternative for formaldehyde detection due to its high sensitivity, selectivity and its potential for providing real-time measurements.

Achmann et al. [5] studied on the sensor electrode with multi walled carbon nanotube films modified with graft percentage of aminogroups modified electrode to detect the concentration of formaldehyde. The result illustrated that the sensor displayed high chemical selectivity, fast response and good reproducibility to low concentration formaldehyde. Amperometric sensors in the potentiostatic mode using noble metals as electrode nanomaterials are also used for formaldehyde detection [6]. Metal nanomaterials have high effective surface areas and extraordinary electron-transport properties. Their using as electrochemical interface provides a rapid current response and highdetection sensitivity. Consequently, the electron transfer between the electrode and the probe molecules is accelerated. Zhang et al. [7]introduced the electrodeposition of a nanostructured palladium in aluminum oxide membrane coated glassy carbon electrode. The proposed sensor not only possesses a broad linear range, good reproducibility and high sensitivity, but also exhibits a synergistic effect that minimizes poison formation. Yi et al. [8] reported a novel formaldehyde detection method based on nanoporous palladium modified $\mathrm{TiO}_{2}$ electrode in alkaline solutions.

Ionic liquids are stable salts, composed of an organic cation and an organic or inorganic anion, and preserved in liquid state over a wide temperature range [9-11]. In the past few years, ionic liquids have emerged as a frontier and novel area of research because of their excellent chemical and physical properties, such as: good solvating properties, high chemical and thermal stability, non-flammability, low toxicity, almost negligible vapor pressure, high conductivity, and wide electrochemical window [12-14]. As green solvents, ionic liquids has been proposed to be very interesting and efficient pasting binders in place of non-conductive organic binders for the preparation of carbon composite electrodes $[15,16]$. Using ionic liquid as a pasting binder, it can be constructed a new generation of carbon composite electrodes with advantages over carbon paste electrodes, such as: high conductivity, fast electron transfer rates, and antifouling properties [17].

There are various known hydrophobic ionic liquids that can be used as binders for construction of these classes of electrodes. These ionic liquids mainly consist of bis (trifluoromethylsulfonyl)imide or hexafluorophosphate anions. On the other hand, several studies showed that carbon nanotubes present strong electrocatalytic activity for a wide range of different materials such as 6-thioguanine [18], epinephrine [19], glutathione [20], dopamine and uric acid [21], ascorbic acid [22], and cytochrome c [23]. Most of the carbon nanotube -based electrodes for electroanalytical applications are based on physical adsorption of carbon nanotubes onto electrode surfaces, usually glassy carbon [24]. However, it is important to note that carbon nanotubes dispersed in mineral oil [18-20] or consolidated into Teflon [25] have been recently used. Ensafi et al. [26] have applied multiwall carbon nanotubes-ionic liquid paste electrode for determination of isoproterenol.

In respect of literature survey, no ionic liquid 1-hexyl-3-methylimidazolium hexafluorophosphate modified carbon nanotube paste electrode was employed towards electrocatalytic oxidation of formaldehyde. The aim of this work presented here is to develop a 1-hexyl-3methylimidazolium hexafluorophosphate modified carbon nanotube paste electrode to form complex with $\mathrm{Ni}^{2+}$, which provided a simple, sensitive, rapid and low-cost sensor for electrocatalytic oxidation of formaldehyde in the alkaline medium.

\section{Materials and Methods}

\subsection{Materials}

Multiwalled carbon nanotubes (MWCNTs) (diameter: $30 \pm 15 \mathrm{~nm}, 95 \%$ purity and length: 5-20 $\mathrm{\mu m})$ was purchased from Aldrich. Graphite powder and high-purity paraffin oil from Fluka were used for fabrication the carbon paste electrode (CPE). Sodium hydroxide, formaldehyde, $\mathrm{NiCl}_{2} .6 \mathrm{H}_{2} \mathrm{O}$ and potassium hexacyanoferrate $\left(\mathrm{K}_{4} \mathrm{Fe}(\mathrm{CN})_{6}\right)$ were purchased from Merck company that were of analytical reagent grade. The 1-hexyl-3-methylimidazolium hexafluorophosphate was from Aldrich. All materials were used without any further 
purification. Also, all solutions were prepared with double distilled water. All solutions were freshly prepared with double distilled water. All other reagents were of analytical grade. The solvent used in this study was twice distilled water.

\subsection{Preparation of Working Electrodes}

The IL/CNPE was prepared by thoroughly mixing $1.0 \mathrm{~g}$ of carbon nanotube powder with $0.25 \mathrm{~g}$ of paraffin oil and about $1.0 \mathrm{~g}$ of ionic liquid in a mortar to form a homogeneous carbon nanotube paste. A portion of the carbon nanotube paste was filled firmly into one end of a glass tube (internal radius $3 \mathrm{~mm}$ ), and a copper wire was inserted through the opposite end to establish an electrical contact. The surface of the IL/CNPE was polished on a piece of weighing paper to obtain a smooth surface just before use. The bare CPE and CNPE were fabricated according to same procedure, with adding paraffin oil $(0.50 \mathrm{~g})$ to graphite $(1.0 \mathrm{~g})$ and carbon nanotube $(1.0 \mathrm{~g})$ powders respectively, for comparison purpose.

\subsection{Instrumentation}

Voltammetric measurements were performed at a Metrohm Computrace Voltammetric Analyzer Model 797 VA with a conventional three-electrode cell. The bare CPE, bare CNPE, ionic liquid modified carbon nanotube paste electrode (IL/CNPE) and nickel/ionic liquid modified carbon nanotube paste electrode (Ni/IL/CNPE) were used as working electrodes. Also, the auxiliary electrode was a platinum rode, and an $\mathrm{Ag}|\mathrm{AgCl}| \mathrm{KCl}(3 \mathrm{M})$ was applied as a reference electrode. During the measurements, the solution in the cell was neither stirred nor aerated. Measurements of $\mathrm{pH}$ were made with a Denver Instrument Model $827 \mathrm{pH}$ meter equipped with a Metrohm glass electrode. Scanning electron microscopy (SEM) (Philips Corp., XL30 model) was used for seeing of the surface morphology of the modified electrodes.

\subsection{Sample Analysis}

$100 \mu \mathrm{L}$ of formalin were diluted in $10 \mathrm{~mL}$ of water and then, an aliquot $(400 \mu \mathrm{L})$ was added to $25 \mathrm{~mL}$ of $0.1 \mathrm{M} \mathrm{NaOH}$ solution and recorded by cyclic voltammetry under optimized experimental conditions. The concentration of formaldehyde was measured from calibration curve. All experiments were performed in triplicate.

\section{Results and Discussion}

\subsection{Characterization of the IL/CNPE}

Potassium ferrocyanide was chosen as a probe to evaluate the performance of the proposed electrodes. Figure 1 illustrates the cyclic voltammograms of the electrochemical oxidation of $\mathrm{K}_{4} \mathrm{Fe}(\mathrm{CN})_{6}$ at the surface of the bare CPE, bare CNPE and IL/CNPE in the 27.00 $\mathrm{mM}$ of $\mathrm{K}_{4} \mathrm{Fe}(\mathrm{CN})_{6}$ solution. As can be seen in Figure 1, the anodic and cathodic peak currents for the bare CNPE is higher than that at the bare CPE and peak currents for the $\mathrm{IL} / \mathrm{CNPE}$ is greater than that of the bare CNPE. The experimental results show reproducible anodic and cathodic peaks ascribed to $\mathrm{Fe}(\mathrm{CN})_{6}^{3-} / \mathrm{Fe}(\mathrm{CN})_{6^{4-}}$ redox couple at slow scan rates at the surface of IL/CNPE. This is a quasi-reversible system because the peak separation potential, $\Delta E_{\mathrm{p}}\left(E_{\mathrm{pa}}-E_{\mathrm{pc}}\right)$, is equal to 288.1 $\mathrm{mV}$ (349-80.9) and is greater than $59 \mathrm{mV}$ that expected for a reversible system. The $\Delta E_{\mathrm{p}}$ of $\mathrm{Fe}(\mathrm{CN})_{6}{ }^{3-} / \mathrm{Fe}(\mathrm{CN})_{6^{4-}}$ redox couple at the surface of the bare CPE was obtained to be $430 \mathrm{mV}$ (as a quasi-reversible system) [27] and is greater than that at the bare CNPE and IL/CNPE.

Electrochemical impedance spectroscopy was widely applied to characterize the interface properties of the electrode [28]. Electrochemical impedance spectroscopy was em-

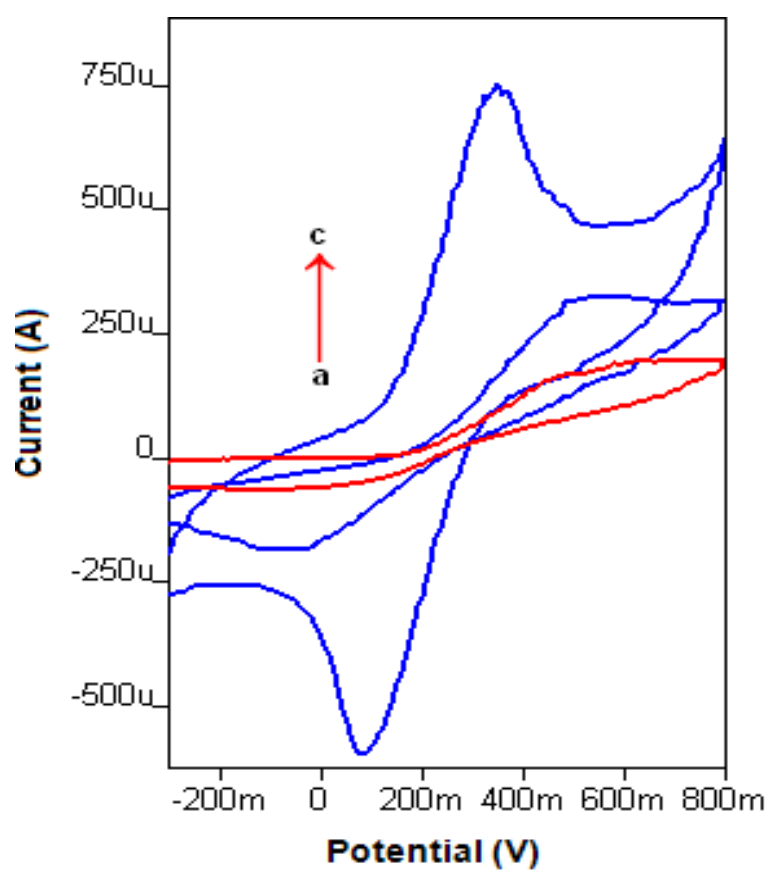

Figure 1. The cyclic voltammograms of 27.00 $\mathrm{mM} \mathrm{K}_{4} \mathrm{Fe}(\mathrm{CN})_{6}$ at the surface of (a) bare $\mathrm{CPE}$, (b) bare CNPE and (c) IL/CNPE in the phosphate buffer solution ( $\mathrm{pH}$ 7.0) at a scan rate of $20 \mathrm{mV} . \mathrm{s}^{-1}$ 
ployed in order to discriminate between the unmodified and modified electrodes. Figure 2 showed the typical Nyquist plots for the unmodified CNPE (a) and IL/CNPE (b) in phosphate buffer solution ( $\mathrm{pH} 7.0$ ) consisting of redox probe $\left[\mathrm{Fe}(\mathrm{CN})_{6}\right]^{3 / 4-}\left(2.0 \times 10^{-3} \mathrm{M}\right)$. It is clear, considerable differences in the electrochemical impedance spectroscopy were observed for these two electrodes.

The unmodified CPE presented a large semicircle in the high frequencies range with a large resistance of electron transference, showing a low electrochemical activity of $\left[\mathrm{Fe}(\mathrm{CN})_{6}\right]^{3-14}$ on the unmodified CPE. This may be due to the presence of oil as an insulating material, which it decreases the electron transfer rate of the $\left[\mathrm{Fe}(\mathrm{CN})_{6}\right]^{3-/ 4}$ redox couple at the electrode surfaces. Notwithstanding, the IL/CNPE showed a quasi-semicircle section of much smaller diameter in the high frequencies range, which was is related to the suitable ionic conductivity of ionic liquid and the lower resistance to electron transfer of the IL/CNPE. The obtained results about the IL/CNPE exhibited that the Nyquist plot is a straight line with a larger slope compared to the unmodified $\mathrm{CNPE}$, at low frequencies, which is related to a diffusion-limited electrochemical process. Based on the results, it was proved that the IL/CNPE could successfully increase the electron transference rate of $\left[\mathrm{Fe}(\mathrm{CN})_{6}\right]^{3 / 4-}$ and obtained very varied features from those of the unmodified CNPE.

\subsection{Surface Morphology of the IL/CNPE}

The surface morphology of the fabricated electrodes was characterized by SEM. Figure 3

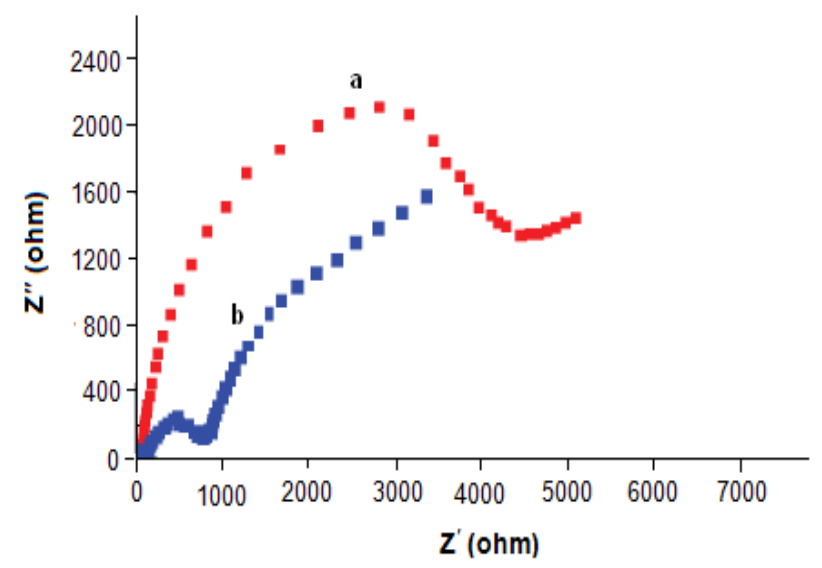

Figure 2. Electrochemical impedance spectroscopy for the (a) unmodified CNPE and (b) IL/CNPE in phosphate buffer solution ( $\mathrm{pH}$ 7.0) containing $2.0 \times 10^{-3} \mathrm{M}[\mathrm{Fe}(\mathrm{CN}) 6]^{3-14}$ at the frequency range from $1 \mathrm{~Hz}$ to $100 \mathrm{kHz}$ shows the SEM images of (a) MWCNTs and (b) IL/CNPE. In the absence of ionic liquid, the MWCNTs are heavily entangled, forming a typical agglomerative structure. However, the SEM recorded for the MWCNTs in the presence of ionic liquid (Figure 3b) shows the formation of a material with gel aspect with MWCNTs wrapped by the ionic liquid architecture. The ionic liquid reduces the agglomeration of the nanotubes, which were more dispersed.

3.3 Incorporation of $\mathrm{Ni}(\mathrm{II})$ Ions into the Electrode

Figure 4 illustrates the (a) Ni/CNPE and (b) $\mathrm{Ni} / \mathrm{IL} / \mathrm{CNPE}$ in $0.1 \mathrm{M} \mathrm{NaOH}$ solution at the potential range from 0.10 to $0.75 \mathrm{~V}$ vs. $\mathrm{Ag}|\mathrm{AgCl}| \mathrm{KCl}(3 \mathrm{M})$ and potential sweep rate of $10 \mathrm{mV} . \mathrm{s}^{-1}$. In order to incorporate $\mathrm{Ni}$ (II) ions into the surface of the electrode, the freshly prepared electrode was placed in a well stirred aqueous solution of $0.5 \mathrm{M} \mathrm{NiSO}_{4}$ at an open circuit for $5 \mathrm{~min}$ (accumulation time, $5 \mathrm{~min}$ ). Afterward, the electrode was transferred into a cell containing $0.1 \mathrm{M} \mathrm{NaOH}$ solution, and potential cycling was performed. It can be de-
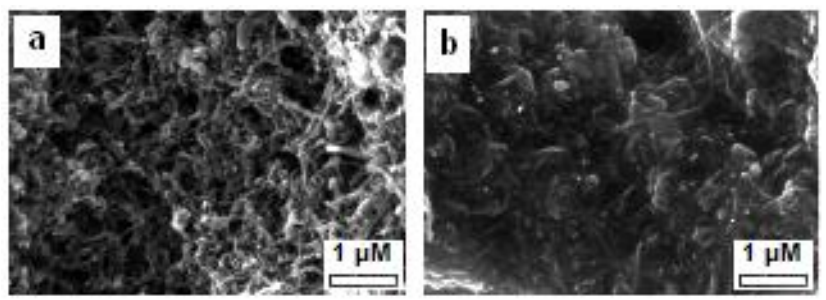

Figure 3. SEM images of (a) MWCNTs and (b) IL/CNPE

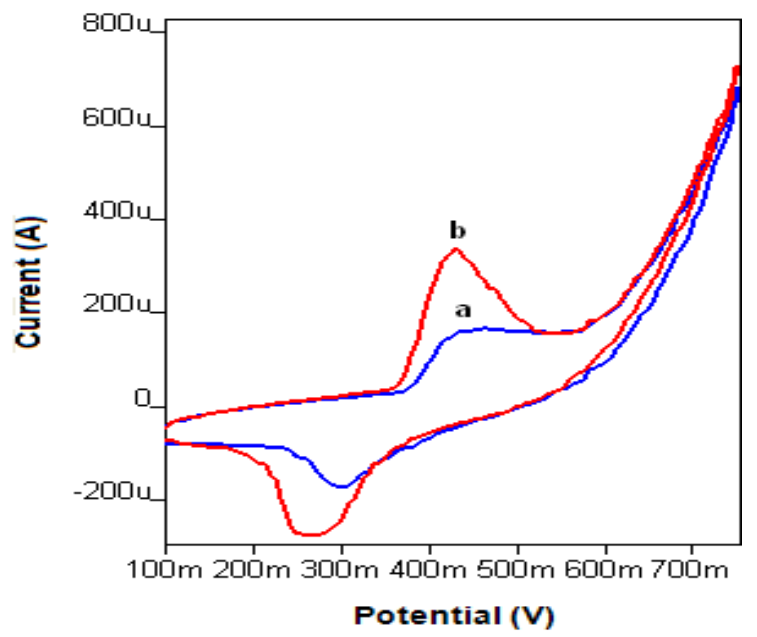

Figure 4. The cyclic voltammograms of (a) $\mathrm{Ni} / \mathrm{CNPE}$ and (b) Ni/IL/CNPE in $0.1 \mathrm{M} \mathrm{NaOH}$ at a scan rate $10 \mathrm{mV} \cdot \mathrm{s}^{-1}$ 
duced that the electrochemical behaviour of Ni/CNPE and Ni/IL/CNPE as modified electrodes in alkaline solution is similar to that of $\mathrm{Ni}$ anode [29]. These redox waves are ascribed to the formation of $\mathrm{Ni}(\mathrm{OH})_{2}$ and then its oxidation at the electrode surface to $\mathrm{NiOOH}$ and reduction of $\mathrm{NiOOH}$ to $\mathrm{Ni}(\mathrm{OH})_{2}$ with a peak potential of 427 and $267 \mathrm{mV}$ vs. $\mathrm{Ag}|\mathrm{AgCl}| \mathrm{KCl}$ (3 $\mathrm{M})$, respectively (Eqs. 1 and 2) [30]:

$$
\begin{aligned}
& \mathrm{Ni}^{2+}+2 \mathrm{OH}^{-} \rightarrow \mathrm{Ni}(\mathrm{OH})_{2} \\
& \mathrm{Ni}(\mathrm{OH})_{2}+\mathrm{OH}^{-} \rightleftarrows \mathrm{NiOOH}+\mathrm{H}_{2} \mathrm{O}+\mathrm{e}^{-}
\end{aligned}
$$

By comparing Figure 4(a) and (b), it can be indicated that the presence of ionic liquid in the electrode construction performed a significant effect to accumulation of nickel species on the surface of electrode. Because, ionic liquid greatly increase the effective surface area and consequently, enhance the electron transfer rate between the electrode surface and $\mathrm{Ni}(\mathrm{OH})_{2}$ [31]. The shoulders in the cathodic peak of Figure 4(b) can be attributed to different crystallographic forms of $\mathrm{Ni}(\mathrm{OH})_{2}$ ( $\alpha$ and $\beta$ phases), as previously reported in other articles [32].

Several working groups have studied the extraction behaviour of "classical" hydrophobic room temperature ionic liquids based on imidazolium cations for different metals (e.g. alkali metals, $\mathrm{Co}, \mathrm{Ni}, \mathrm{Zn}, \mathrm{Mn}$ ) from aqueous solutions [33]. The X-ray photoelectron spectroscopy (XPS) analyses proved that the interaction

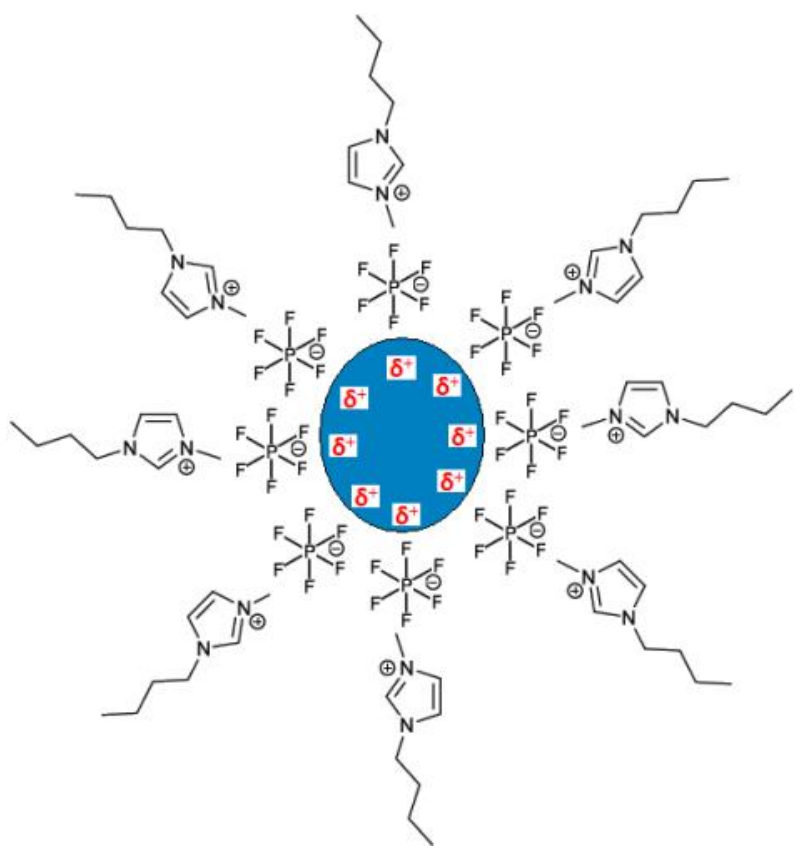

Figure 5. Schematic depiction of proposed interactions between immediate IL anions and the metal nanoparticle surface with the ILcations forming the second shell of the ionic double layer around a metal nanoparticle between the metal surface and the IL occurs through $\mathrm{F}$, when the anion is $\left[\mathrm{BF}_{4}\right]^{-}$of $\left[\mathrm{PF}_{6}\right]^{-}$or through $\mathrm{O}$ with the triflate, $\left[\mathrm{CF}_{3} \mathrm{SO}_{3}\right]^{-}$anion [34].Consequently, one would assume that the ionic multilayer is composed of anions located immediately adjacent to the nanoparticle surface (Figure 5) [34,35]. Also, imidazolium cations through their imidazolium -C-H groups can form hydrogen bonds to the fluorine or oxygen atoms of the IL anions [34,35]. Metal nanoparticles can possess hydroxido and/or oxido ligands on their surface, which can also hydrogen bond with ionic liquids [34]. The IL cationanion hydrogen bond and metal nanoparticle hydrogen bond compete with each other and contribute to metal nanoparticle stabilization in ionic liquids, as shown in Figure 6.

3.4 Electrocatalytic Oxidation of Formaldehyde at the $\mathrm{Ni} / \mathrm{IL} / \mathrm{CNPE}$

In this work, the oxidation of formaldehyde was studied at the surface of $\mathrm{Ni} / \mathrm{IL} / \mathrm{CNPE}$ by cyclic voltammetric experiments in $0.1 \mathrm{M}$ $\mathrm{NaOH}$ solution. Typical results obtained for a potential range from 0.10 to $0.75 \mathrm{~V}$ vs. $\mathrm{Ag}|\mathrm{AgCl}| \mathrm{KCl}(3 \mathrm{M})$ at the potential scan rate of $10 \mathrm{mV} \cdot \mathrm{s}^{-1}$ were shown in the Figure 7 . For comparison, cyclic voltammgrams IL/CNPE was illustrated in $0.1 \mathrm{M} \mathrm{NaOH}$ solution containing $30.00 \mathrm{mM}$ formaldehyde (Figure 7(a)). Comparison of curves (a), (b) and (c) in Figure 7 shows that in the presence of formaldehyde, an increase in current was observed at the surface of Ni/IL/CNPE (Figure 7(c)). It can be demonstrated that the oxidation of formalde-

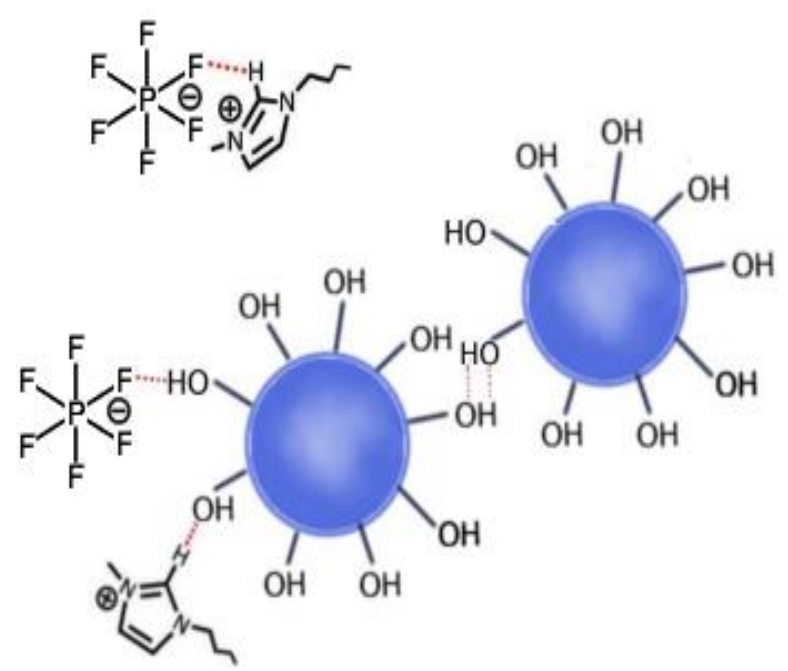

Figure 6. Hydrogen bonds formed between the surface hydroxyl- groups of nanoparticles and ions of ionic liquids, and between cations and anions of ionic liquids 
hyde gives rise to a typical electrocatalytic response, with an increase in the anodic peak current and a decrease in the cathodic peak current. The oxidation potential of $\mathrm{Ni}(\mathrm{OH})_{2}$ in the presence of formaldehyde is observed at ca. $624 \mathrm{mV}$ that is positive than the potential observed for $\mathrm{Ni}^{2+}$ to $\mathrm{Ni}^{3+}$ transition at the surface of Ni/IL/CNPE in the absence of formaldehyde (i.e. $427 \mathrm{mV}$ ).

It can be specified that the formaldehyde molecule is completely hydrated and converted to the methylene glycol $\left(\mathrm{CH}_{2}(\mathrm{OH})_{2}\right)$ with an equilibrium constant on the order of $10^{3}$ in aqueous solution [36]. The methylene glycol exists predominantly in its ionized form $\left(\mathrm{CH}_{2}(\mathrm{OH}) \mathrm{O}^{-}\right)$in $0.1 \mathrm{M} \mathrm{NaOH}$ solution due to its $\mathrm{p} K_{\mathrm{a}}$ of ca. 12.8. When $\mathrm{CH}_{2}(\mathrm{OH}) \mathrm{O}$ - diffuses from the bulk solution to the electrode surface and is quickly oxidized to $\mathrm{CH}_{2}(\mathrm{O}) \mathrm{O}^{-}$by the $\mathrm{NiOOH}$ species on the surface of Ni/IL/CNPE. Therefore, the amount of $\mathrm{NiOOH}$ species decreases due to its chemical reaction with $\mathrm{CH}_{2}(\mathrm{OH}) \mathrm{O}$. In the overall reaction, formaldehyde can be converted to the $\mathrm{CH}_{2}(\mathrm{O}) \mathrm{O}^{-}$and generated one electron (see Figure 8) [37]. Simply, this behaviour is a typical observation expected from the mediated oxidation ( $\mathrm{EC}^{\prime}$ mechanism), illustrated in the following equations:

$$
\begin{aligned}
& \mathrm{Ni}(\mathrm{OH})_{2}+\mathrm{OH}^{-} \rightleftarrows \mathrm{NiOOH}+\mathrm{H}_{2} \mathrm{O}+\mathrm{e}^{-} \mathrm{E} \\
& \mathrm{NiOOH}+\mathrm{CH}_{2}(\mathrm{OH}) \mathrm{O}^{-} \rightarrow \mathrm{Ni}(\mathrm{OH})_{2}+\mathrm{CH}_{2}(\mathrm{O}) \mathrm{O}^{-} \mathrm{C}^{\prime}
\end{aligned}
$$

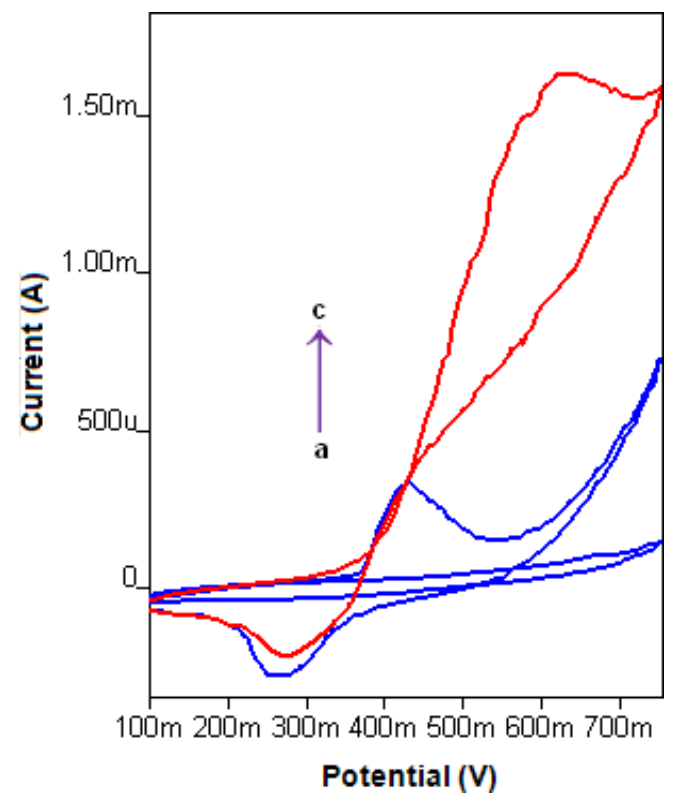

Figure 7. The cyclic voltammograms of (a) IL/CNPE, (b) Ni/IL/CNPE in $0.1 \mathrm{M} \mathrm{NaOH}$ and (c) $\mathrm{Ni} / \mathrm{IL} / \mathrm{CNPE}$ in $0.1 \mathrm{M} \mathrm{NaOH}$ containing $30.00 \mathrm{mM}$ formaldehyde at a scan rate of 10 $\mathrm{mV} . \mathrm{s}^{-1}$
The electrochemical behaviour of $\mathrm{Ni} / \mathrm{IL} / \mathrm{CNPE}$ was investigated in $0.1 \mathrm{M} \mathrm{NaOH}$ at various scan rates. Figure $9 \mathrm{~A}$ shows the cyclic voltammograms of $\mathrm{Ni} / \mathrm{IL} / \mathrm{CNPE}$ in $0.1 \mathrm{M}$ $\mathrm{NaOH}$ solution at different potential sweep rates. As can be seen, the anodic and cathodic currents were enhanced with increasing of scan rate and a potential moved to positive values. The positive shift may be due to the kinetic limitation in diffusion layer which created at high current density. The $\Delta E_{\mathrm{p}}$ was increased with scan rate that indicated a limitation in the charge transfer kinetics. Obviously, the anodic and cathodic peak currents are linearly proportional to the potential sweep rate at low values from 10 to $50 \mathrm{mV} . \mathrm{s}^{-1}$ (Figure 9B). The electrode surface coverage $\left(\Gamma^{*}\right)$ can be calculated from the linear part of the plot and using the following equation which correspond to reversible process with adsorbed species [38].

$$
I_{\mathrm{p}}=\left(n^{2} F^{2} / 4 R T\right) v A \Gamma^{*}
$$

where, $I_{\mathrm{p}}, n, \Gamma^{*}$, and $A$ are the peak current, the number of electrons involved in the reaction $(n=1)$, the surface coverage of the redox species and the surface area of the electrode $\left(0.28 \mathrm{~cm}^{2}\right)$, respectively. The total surface coverage of the immobilized active species $[\mathrm{Ni}(\mathrm{II})]$ is found to be about $2.74 \times 10^{-8} \mathrm{~mol} . \mathrm{cm}^{-2}$, considering the mean of both anodic and cathodic currents. At scan rates larger than 75 $\mathrm{mV} . \mathrm{s}^{-1}$, both the anodic and cathodic peak currents depend on root mean square of scan rate $\left(v^{1 / 2}\right)$ that express a diffusion controlled process dominates with increasing the scan rates (see Figure 9C). This limiting-diffusion process can be related to the charge neutralization of the electrode surface during the oxidation/reduction process [39].

The effect of $v$ on peak potential was also investigated by voltammetry. With the increase

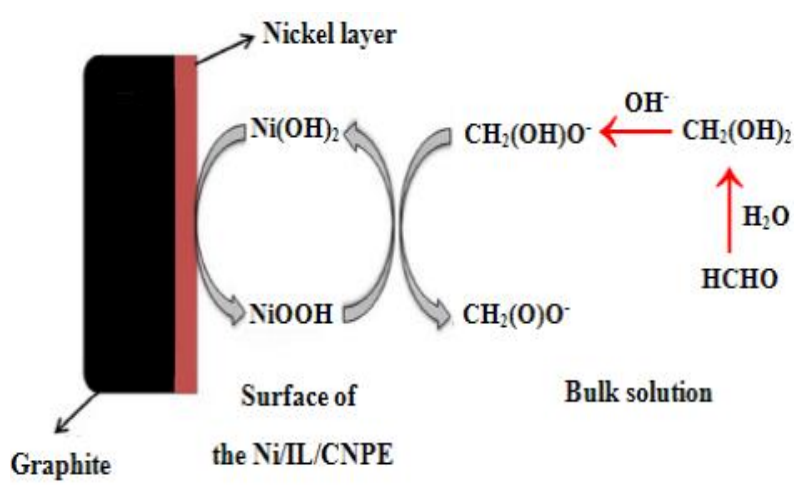

Figure 8. Representative schematic for mechanism of formaldehyde electrooxidation at the surface of $\mathrm{Ni} / \mathrm{IL} / \mathrm{CNPE}$ 
of $v$, the oxidation peak potential is positively shifted, and the reduction peak potential is negatively shifted, indicating that the redox reversibility of nickel oxide film was impaired. Under the surface controlled redox process, the electron transfer kinetics of nickel oxide film on the surface of the Ni/IL/CNPE can be obtained by using the approach developed by Laviron [40]; when peak to peak separation is higher than $200 \mathrm{mV} / \mathrm{n}$, the relationship between the peak potential, $E_{\mathrm{p}}$, and the scan rate can be expressed in Eq. 4:

$$
E_{\mathrm{p}}=\mathrm{f}(\log v)
$$

Figure 9D provided the variations of peak potentials with the logarithm of the scan rate in the ranges of $10-500 \mathrm{mV} \mathrm{s}^{-1}$ for both anodic and cathodic peaks that data extracted from cy- clic voltammograms of the Ni/IL/CNPE in 0.1 $\mathrm{M} \mathrm{NaOH}$ solution. It can be observed that $E_{\mathrm{p}}$ is proportional to $\log v$ at $v>50 \mathrm{mV} \mathrm{s}^{-1}$. From the slope of the oblique asymptotes, where for cathodic peak, the slope value is $-2.3 R T / a n F$, and for anodic peak, 2.3RT/(1-a)nF, the electron transfer coefficient $(a)$ of nickel oxide film was calculated. Furthermore, the standard rate constant of reaction, $k_{\mathrm{s}}$, is expressed in Eq. 5 [40]:

$\log k_{\mathrm{s}}=a \log (1-a)+(1-a) \log a-\log (R T / n F v)-[a$ $\left.(1-a) n F \Delta E_{\mathrm{p}}\right] /(2.3 R T)$

where, $\Delta E_{\mathrm{p}}$ is the peak to peak potential separation. The resulting values of $a$ and $k_{\mathrm{s}}$ were obtained 0.32 and $2.37 \times 10^{-1} \mathrm{~cm} . \mathrm{s}^{-1}$, respectively. Figure 10A displays the cyclic voltammograms of $\mathrm{Ni} / \mathrm{IL} / \mathrm{CNPE}$ in $0.1 \mathrm{M} \mathrm{NaOH}$ solution
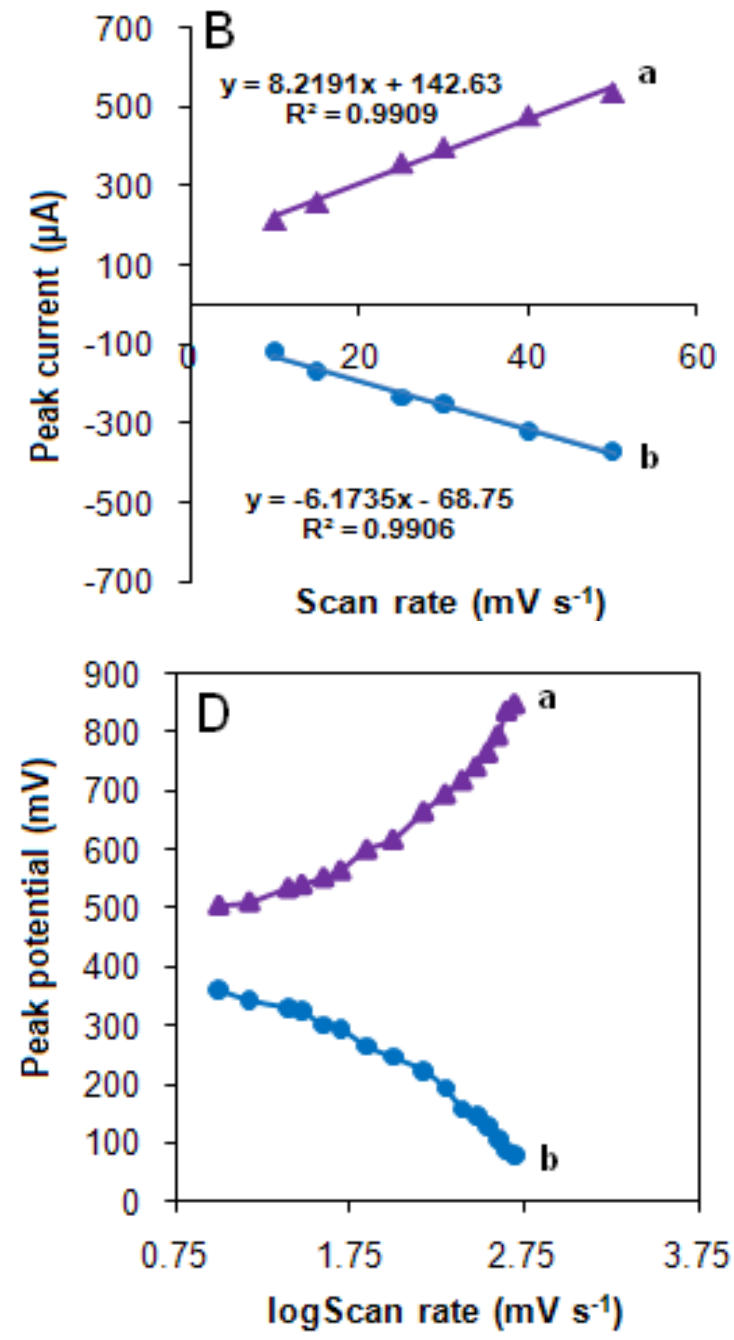

Figure 9. (A) The cyclic voltammograms of Ni/LL/CNPE in $0.1 \mathrm{M} \mathrm{NaOH}$ at some scan rates from (a) to (h): 10, 20,30,50,75, 200, 300 and $500 \mathrm{mV} \cdot \mathrm{s}^{-1}$. (B) The dependency of $I_{\mathrm{pa}}$ (a) and $I_{\mathrm{pc}}$ (b) on $v$ at lower values of $v\left(10-50 \mathrm{mV} \cdot \mathrm{s}^{-1}\right)$, and (C) the plot of $I_{\mathrm{pa}}(\mathrm{a})$ and $I_{\mathrm{pc}}(\mathrm{b})$ on $v^{1 / 2}$ at higher values of $v(v>$ $\left.75 \mathrm{mV} . \mathrm{s}^{-1}\right)$. (D) Plot of $E_{\mathrm{p}}$ vs. $\log v$ for cyclic voltammograms recorded at the surface of Ni/IL/CNPE in $0.1 \mathrm{M} \mathrm{NaOH}$ solution; (a) for anodic peaks and (b) for cathodic peaks 
containing $4.0 \mathrm{mM}$ formaldehyde at different potential sweep rates. Also, Figure $8 \mathrm{~B}$ presents a plot of scan rate normalized current $\left(I_{\mathrm{pa}} / v^{1 / 2}\right)$ vs logarithm scan rate (log $v$ ) obtained based on data of Figure 10A. Figure 10B appears the characteristic shape of an $\mathrm{EC}^{\prime}$ process which express that the electrode reaction is coupled with an irreversible follow up chemical step $[41,42]$.

Comparison of the various parameters obtained here in our study with the literatures can be given to further evaluate the present electrode, Ni/IL/CNPE. Table 1 lists the values of the anodic peak potential, $E_{\mathrm{pa}}$ and the cur- rent density, I, of the formaldehyde electrochemical oxidation and the formaldehyde concentration used to generate the corresponding current density [43-48]. As can be seen from the Table, it seems clearly that nickel hydroxide in the Ni/IL/CNPE can act as a comparable catalyst in the oxidation of formaldehyde and the obtained values here in this work are better than in many cases and comparable with others. Besides, the surface modification of the electrode is simple and reproducible compared that some modified electrodes and this novel catalyst can be utilized in fuel cell system.

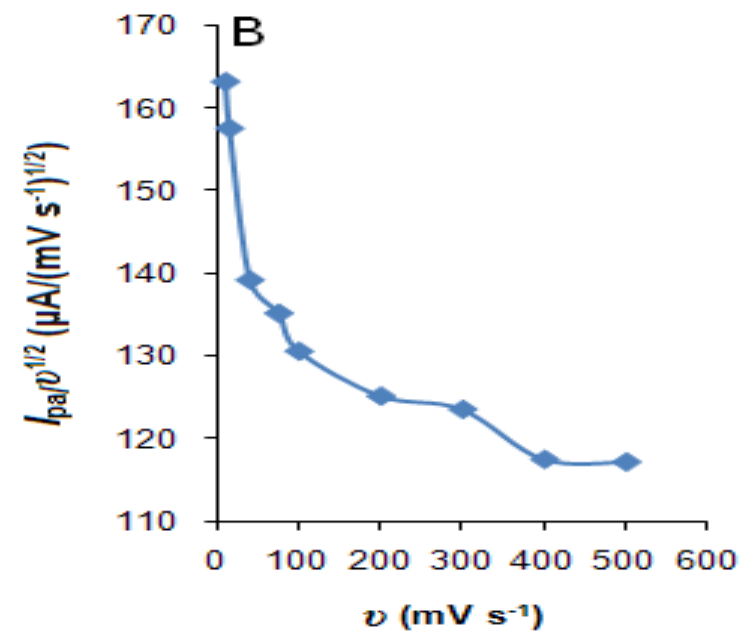

Figure 10. (A) The cyclic voltammograms of Ni/IL/CNPE in $0.1 \mathrm{M} \mathrm{NaOH}$ consisting of $30.00 \mathrm{mM}$ formaldehyde at some scan rates from (a) to (i): 10, 15, 40, 75, 100, 200, 300, 400 and 500 mV.s ${ }^{-1}$. (B) The plot of the normalized anodic peak currents $\left(I_{\mathrm{pa}} / v^{1 / 2}\right)$ of cyclic voltammograms of the (A) vs. scan rate in the presence of $30.00 \mathrm{mM}$ formaldehyde at the mentioned scan rates

Table 1. Comparison of the electrocatalytic behavior of Ni/IL/CNPE for oxidation of formaldehyde with some of the previously reported electrodes

\begin{tabular}{|c|c|c|c|c|c|}
\hline Electrode & Electrolyte & $\begin{array}{c}\text { Formaldehyde } \\
\left(\mathrm{mol} \mathrm{L}^{-1}\right)\end{array}$ & $\begin{array}{c}E_{\mathrm{pa}} / \mathrm{V} v s \\
(\mathrm{Ag} / \mathrm{AgCl})\end{array}$ & $I / \mathrm{mA} \mathrm{cm}^{-2}$ & Ref. \\
\hline $\mathrm{Ni} / \mathrm{P}-\mathrm{CPE}^{\mathrm{a}}$ & $0.1 \mathrm{M} \mathrm{NaOH}$ & 0.035 & 0.62 & 15.0 & {$[43]$} \\
\hline $\mathrm{Ni}-\mathrm{CoVSB}-5 / \mathrm{CPE}^{\mathrm{b}}$ & $0.1 \mathrm{M} \mathrm{NaOH}$ & 0.05 & 0.60 & 2.29 & {$[44]$} \\
\hline $\mathrm{Ni} / \mathrm{P}(1,5-\mathrm{DAN}) / \mathrm{MCPE}^{\mathrm{c}}$ & $0.1 \mathrm{M} \mathrm{NaOH}$ & 0.17 & 0.80 & 7.6 & {$[45]$} \\
\hline $\begin{array}{l}\mathrm{Ni}(\mathrm{OH})_{2} / \mathrm{POT}(\mathrm{TX}- \\
\text { 100)/MCNTPE }\end{array}$ & $0.1 \mathrm{M} \mathrm{NaOH}$ & 0.048 & 0.70 & 12.70 & {$[46]$} \\
\hline Pt/Carbon-Ceramic & $0.1 \mathrm{M} \mathrm{H}_{2} \mathrm{SO}_{4}$ & 0.75 & 0.85 & 31.40 & {$[47]$} \\
\hline $\begin{array}{l}\mathrm{Cu} / \mathrm{P}(2 \mathrm{ADPA}) / \\
\mathrm{MCNTPE}^{\mathrm{f}}\end{array}$ & $0.2 \mathrm{M} \mathrm{NaOH}$ & 0.17 & 0.63 & 25.56 & {$[48]$} \\
\hline $\mathrm{Ni} / \mathrm{IL} / \mathrm{CNPE}$ & $0.1 \mathrm{M} \mathrm{NaOH}$ & 0.03 & 0.62 & 29.44 & This study \\
\hline
\end{tabular}

aNickel doped $\mathrm{P}$ nanozeolite carbon paste electrode

bNanoporous cobalt-nickel phosphate VSB-5 molecular sieve modified carbon paste electrode

cNi/poly (1, 5-diaminonaphthalene)-modified carbon paste electrode

${ }^{\mathrm{d}} \mathrm{Ni}(\mathrm{OH})_{2} /$ poly (o-toluidine)/Triton X-100 film modified carbon nano-tube paste electrode

ePlatinum nanoparticles decorated carbon-ceramic substrate

fCopper-poly (2-aminodiphenylamine) composite modified carbon nano-tube paste electrode 
3.5 Effect of Experimental Parameters on the Ni/IL/CNPE Performance

\subsubsection{Effect of accumulation time}

In order to study this factor, voltammetric responses of the $\mathrm{Ni} / \mathrm{IL} / \mathrm{CNPE}$ at the three different accumulation times 1.0, 1.5, and 5.0 min were performed by cyclic voltammetry technique at $0.1 \mathrm{M} \mathrm{NaOH}$ solution containing $30.00 \mathrm{mM}$ formaldehyde. The value of $\Delta I_{\mathrm{p}}$ increased gradually with increasing of accumulation times. The maximum value was got at 1.0 min then decreased, so $1.0 \mathrm{~min}$ was chosen as the optimum time, which indicated that probably surface active sites of modified electrode get saturated at $1.0 \mathrm{~min}$ and at the other times, this may be due to the fact that based on Eq. 1, the excess amount of $\mathrm{Ni}(\mathrm{OH})_{2}$ present on the electrode surface, the electrode conductivity decreases (Figure 11).

\subsubsection{Effect of $\mathrm{Ni}^{2+}$ ions concentration}

The effect of the amount of nickel on response of the Ni/IL/CNPE was studied at accumulation time $1.0 \mathrm{~min}$ by varying the concentration of nickel chloride $(0.25,0.50,1.0$, and $1.5 \mathrm{M}$ ) in the deposition bath in $0.1 \mathrm{M} \mathrm{NaOH}$ solution containing $30.00 \mathrm{mM}$ formaldehyde. It was observed that as the concentration of $\mathrm{Ni}$ in the bath increased, the formaldehyde oxidation currents also increased up to $0.5 \mathrm{M}$; after which, it decreased (Figure 12). According to Eq. 1, it may be due to the excessive presence of $\mathrm{Ni}(\mathrm{OH})_{2}$ on the modified electrode surface reduces the electrode conductivity.

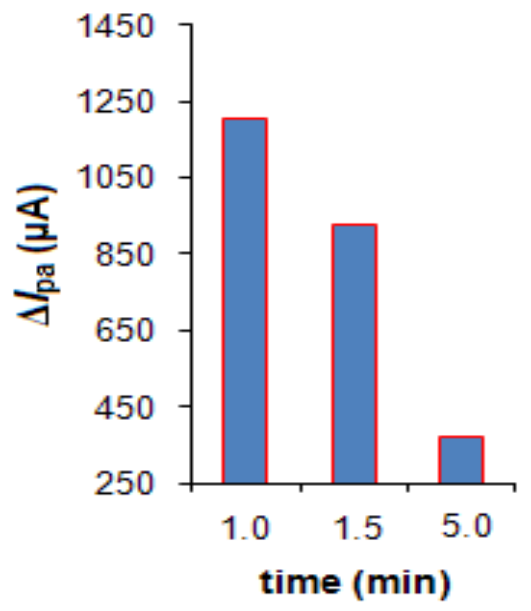

Figure 11. Effect of accumulation time on difference between anodic peak currents $\left(\Delta I_{\text {pa }}\right)$ of the Ni/IL/CNPE (immersed in $0.5 \mathrm{M} \mathrm{NiCl}_{2}$ solution) in the absence and the presence of 30.00 $\mathrm{mM}$ formaldehyde in $0.1 \mathrm{M} \mathrm{NaOH}$ at scan rate of $10 \mathrm{mV} \cdot \mathrm{s}^{-1}$

\subsubsection{Effect of $\mathrm{NaOH}$ concentration}

For this purpose, the experiments were carried out with the $\mathrm{Ni} / \mathrm{IL} / \mathrm{CNPE}$ in different $\mathrm{NaOH}$ solutions $(0.01,0.1$ and $1.0 \mathrm{M})$. The values of $\Delta I_{\mathrm{p}}$ were measured from the cyclic voltammograms of $\mathrm{Ni}(\mathrm{OH})_{2} / \mathrm{NiOOH}$ oxidation the absence and presence of formaldehyde that higher anodic current difference was obtained in $0.1 \mathrm{M} \mathrm{NaOH}$ (Figure 13). It is suggested that at low concentration of $\mathrm{NaOH}$, the formed amount of $\mathrm{Ni}(\mathrm{OH})_{2}$ is low in the surface of modified electrode. Also, with increasing $\mathrm{NaOH}$, over than $0.1 \mathrm{M}$, the anodic peak currents difference of the Ni/IL/CNPE in the absence and presence of formaldehyde decreases. It may be due to the electrode conductivity decreases by the excessive presence of $\mathrm{Ni}(\mathrm{OH})_{2}$ on the electrode surface.

\subsection{Calibration Curve}

The cyclic voltammograms were recorded for calibration graph construction on the $\mathrm{Ni} / \mathrm{IL} / \mathrm{CNPE}$ under the optimum conditions described above using standard addition method as presented in Figure 14A. Under all the optimized experiment conditions, the anodic peak current obtained from cyclic voltammograms of formaldehyde on the Ni/IL/CNPE was proportional to the concentration of formaldehyde in two concentration ranges of $7.00 \times 10^{-6}$ to $9.60 \times 10^{-5} \mathrm{~mol}^{-1}$ (Figure $14 \mathrm{~B}$ ) and $9.60 \times 10^{-5}$ to $32.00 \times 10^{-3} \mathrm{~mol}^{-1}$ (Figure $14 \mathrm{C}$ ), respectively. The proposed method presented an excellent detection limit of $9.50 \times 10^{-7}$ mol.L-1 $^{-1}$

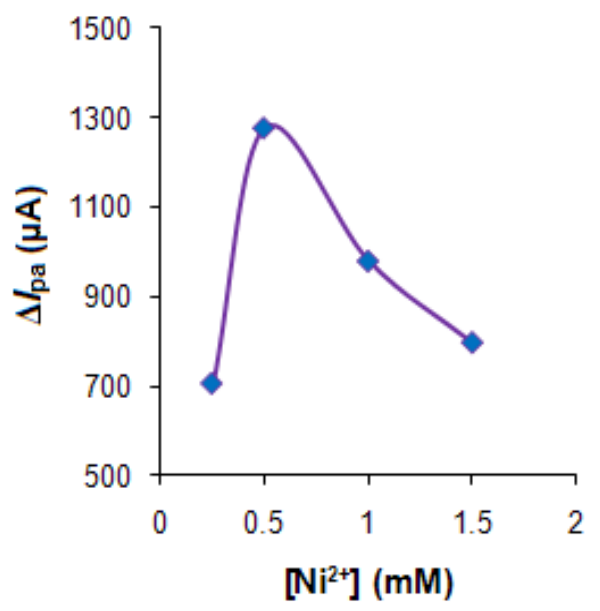

Figure 12. Effect of nickel concentration on difference between anodic peak currents $\left(\Delta I_{\mathrm{pa}}\right)$ of the Ni/IL/CNPE (accumulation time $1.0 \mathrm{~min}$ ) in the absence and the presence of $30.00 \mathrm{mM}$ formaldehyde in $0.1 \mathrm{M} \mathrm{NaOH}$ at scan rate of 10 $\mathrm{mV} . \mathrm{s}^{-1}$ 
(3o/slope). Since the acceptable detection limit according to the standards of Occupation Safety and Health Administration (OSHA), varies from 0.1 to $1 \mathrm{mM}$ formaldehyde [20], therefore, this sensor offers very low detection limit the quantification of formaldehyde. Also, the simplicity of the electrode preparation is a main advantage of this method for determination of formaldehyde. The comparison of several parameters of formaldehyde at some modified electrodes is listed in Table 2 . It can be seen from the table that the detection limit and linear range obtained in this study are comparable with values reported by other research groups for the electrocatalytic oxidation of formalde-

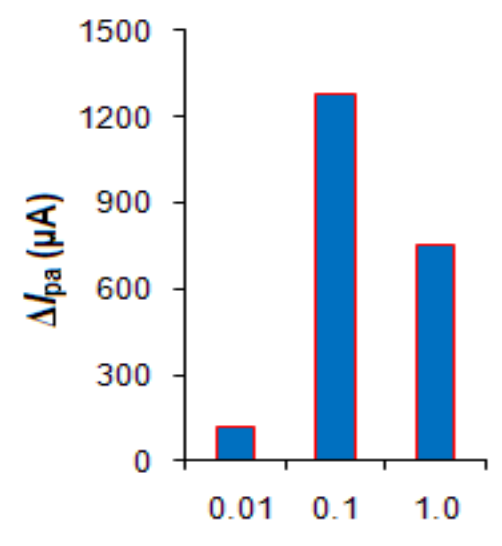

[NaOH] (mM)

Figure 13. Influence of $\mathrm{NaOH}$ concentration on difference between anodic peak currents $\left(\Delta I_{\mathrm{pa}}\right)$ of the Ni/IL/CNPE (accumulation time $1.0 \mathrm{~min}$ and immersed in $0.5 \mathrm{M} \mathrm{NiCl}_{2}$ solution) in the absence and the presence of $30.00 \mathrm{mM}$ formaldehyde at scan rate of $10 \mathrm{mV} . \mathrm{s}^{-1}$ hyde on the surface of chemically modified electrodes by other mediators [8,49-52].

\subsection{Repeatability and Stability of the Ni/IL/ CNPE}

To evaluation and confirmation the repeatability of $\mathrm{Ni} / \mathrm{IL} / \mathrm{CNPE}$, five repeatedly cyclic voltammetry was performed under the optimized conditions. The anodic peak currents of $\mathrm{Ni} / \mathrm{IL} / \mathrm{CNPE}$ to electrocatalytic oxidation of $30.00 \mathrm{mM}$ formaldehyde were tested and the relative standard deviation (RSD) was $6.8 \%$ for five measurements. This result showed that the repeatability of the electrode is suitable. The stability of the electrode was estimated using monitoring of the electrode response to electrocatalytic oxidation of $30.00 \mathrm{mM}$ formaldehyde after being stored at room temperature for 15 days. It was observed that, the current response preserved almost $91 \%$ of its initial amounts.

\subsection{Real Sample Analysis}

In order to demonstrate the capability of the Ni/IL/CNPE toward determination of formaldehyde in a real sample, this modified electrode was used in voltammetric determination of formaldehyde in formalin. The determination of formaldehyde was carried out by the standard addition method. The data obtained for analysis formaldehyde by this method have been illustrated for several times in Table 3. Also, in order to investigate the proposed method the same sample was analyzed using sodium sulfite titration method in acidic solution as an official method [53]. The results have been summarized in Table 3. As it can be seen, the re-
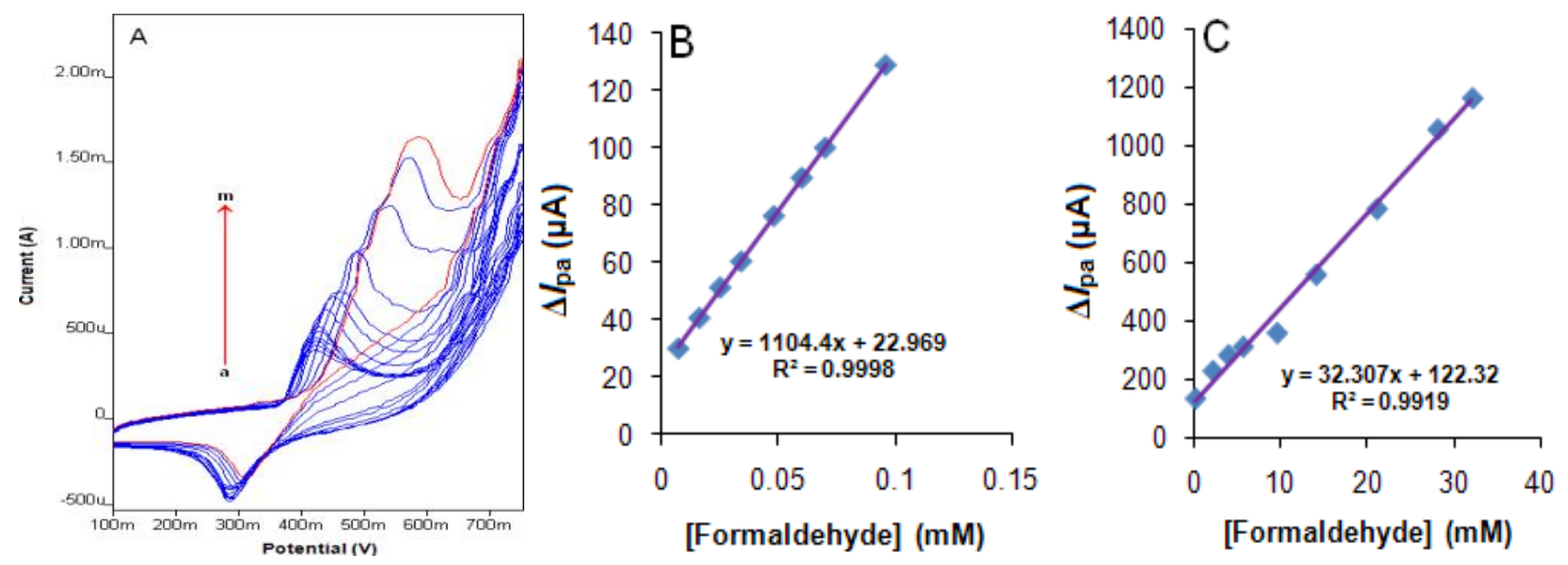

Figure 14. (A) The cyclic voltammograms for different concentrations of formaldehyde, (a) 0.0 (b) 0.007, (c) 0.016, (d) 0.034, (e) 0.070, (f) 0.096, (g) 2.10, (h) 3.90, (i) 5.60, (j) 14.00, (k) 21.00, (l) 2800 and (m) 32.00 in $0.1 \mathrm{M} \mathrm{NaOH}$ on the Ni/IL/CNPE at optimized cyclic voltammetry parameters. (B) and (C) Calibration curves for the determination of formaldehyde 
sults obtained from the two methods are in good agreement and confirm the reliability of the proposed method. A statistical test ( $F$-test) was used to confirm the precision of the proposed method. As it can be seen, $F$-test results bear a noticeable difference from the critical value (19.00 in four degrees of freedom and 95 $\%$ of confidence). Moreover, a statistical $t$-test was performed to evaluate the accuracy of the proposed method. The results suggested that there is no evidence of systematic difference between the results obtained by either of the methods. Four degrees of freedom and $95 \%$ of confidence as well as the critical $t$-value (2.78) were used to support the conclusions of this test.

\section{Conclusions}

In this paper, it was firstly described, that ionic liquid 1-hexyl-3-methylimidazolium hexafluorophosphate has been used for bulk modified CNPE fabrication (IL/CNPE). Characterization results of the IL/CNPE using electrochemical impedance spectroscopy and cyclic voltammetry showed that the ionic liquid increases the electron transfer rate and reversi- bility of the electrode. Also, scanning electron microscopy was used for investigation of the surface morphology of IL/CNPE. On the other hand, the prepared Ni/IL/CNPE by immersion of the IL/CNPE into $\mathrm{NiCl}_{2}$ solution, presented reasonable catalytic performance for the electrocatalytic oxidation of formaldehyde. Electrocatalysis of formaldehyde oxidation is sensitive to various parameters such as accumulation time, nickel amount and $\mathrm{NaOH}$ concentration. This new and simple sensor showed promising determination of formaldehyde with excellent detection limit and comparable with values reported by other research groups. The $\mathrm{Ni} / \mathrm{IL} / \mathrm{CNPE}$ can be successfully used as a voltammetric sensor for formaldehyde determination in real sample with suitable precision and accuracy.

\section{References}

[1] Norouzi, B., Sarvinehbaghi, S., Norouzi, M. (2014). Electrocatalytic Oxidation of Formaldehyde on Ni/Poly(N,N-Dimethylaniline) (Sodium Dodecylsulfate) Modified Carbon Paste Electrode in Alkaline Medium. Russian Journal of Electrochemistry, 50: 1020-1026.

Table 2. Comparison some of the analytical parameters of the different modified electrodes for formaldehyde determination

\begin{tabular}{lcccc}
\hline Electrode & Method & LDR $(\mathrm{mM})$ & LOD $(\mathrm{mM})$ & Ref. \\
\hline PTOE $^{\mathrm{c}}$ & Chronoamperometry & $2.5-17.7$ & 0.015 & {$[8]$} \\
AOXISFET $^{\mathrm{a}}$ & Potentiometry & $5-200$ & - & {$[49]$} \\
$\mathrm{CNFGNPGE}^{\mathrm{b}}$ & Amperometry & $0.01-1$ & - & {$[50]$} \\
$\mathrm{Bio-functionalized}_{\mathrm{Si} / \mathrm{SiO}_{2} / \mathrm{Si}_{3} \mathrm{~N}_{4}{ }^{\mathrm{d}}}$ & Capacitance-voltage & $0.01-20$ & 0.01 & {$[51]$} \\
$\mathrm{AgPd} / \mathrm{Ch}-\mathrm{IL} / \mathrm{GCE}$ & measurements & & & \\
$\mathrm{Ni} / \mathrm{IL} / \mathrm{CNPE}$ & Amperometry & $0.060-20$ & 0.022 & {$[52]$} \\
& Cyclic voltammetry & $0.007-0.096$ and & 0.00095 & This study \\
& & $0.096-32.0$ & & \\
\hline
\end{tabular}

aHighly or partially purified alcohol oxidase immobilized on the ion sensitive field effect transistor ${ }^{b}$ Cathodic electrode position paints modified with $\mathrm{Os}(\mathrm{bpy})_{2} \mathrm{Cl}$ complexes-NAD ${ }^{+}$-formaldehyde dehydrogenase-glutathione-nafion architecture modifiedplatinized graphite electrode

cPalladium modified $\mathrm{TiO}_{2}$ electrode

dFunctionalized using $\mathrm{NAD}^{+}$- and glutathione-dependent recombinant formaldehyde dehydrogenase

eGlassy carbon modified AgPd alloy nanoparticles on chitosan-ionic liquid film

Table 3. Comparison of results for the Ni/IL/CNPE sensor with those from titration official method for formaldehyde determination in formalin sample

\begin{tabular}{ccccccc}
\hline \multirow{2}{*}{ Labled $^{\mathrm{a}}$} & \multicolumn{2}{c}{ Proposed method } & \multicolumn{2}{c}{ Official method } & \multirow{2}{*}{$t_{\exp }$} & $F_{\exp }$ \\
\cline { 2 - 5 } & Founda,b & Recovery(\%) & Founda,b & Recovery(\%) & & \\
\hline 13.32 & 12.75 & 95.72 & 12.80 & 96.10 & 0.14 & 11.35 \\
\hline
\end{tabular}

aUnit based on $\mathrm{mol} \mathrm{L}^{-1}$

bAverage of three replicate measurements 
[2] Gerberich, H.R., Seaman, G.C. (1994). Formaldehyde: Encyclopedia of Chemical Technology. $4^{\text {th }}$ ed., vol. 11, Wiley, New York, p. 929.

[3] Patnaik, P. (1997). Handbook of Environmental Analysis: Chemical Pollutants in Air, Water, Soil, and Solid Wastes. CRC Press, Boca Raton, FL.

[4] Flyvholm, M.A., Andersen, P. (1993). Identification of Formaldehyde Releasers and Occurrence of Formaldehyde and Formaldehyde Releasers in Registered Chemical Products. American Journal of Industrial Medicine, 24: 533-552.

[5] Xie, H., Sheng, C., Chen, X., Wang, X., Li, Z., Zhou, J. (2012). Multi-Wall Carbon Nanotube Gas Sensors Modified with Amino-Group to Detect Low Concentration of Formaldehyde. Sensors and Actuators B Chemical, 168: 3438.

[6] Del Torno-de Román, L., Alonso-Lomillo, M.A., Domínguez-Renedo, O., MerinoSánchez, C., Merino-Amayuelas, M.P., ArcosMartínez, M.J. (2011). Fabrication and Characterization of Disposable Sensors and Biosensors for Detection of Formaldehyde. Talanta, 86: 324-328.

[7] Zhang, Y., Zhang, M., Cai, Z., Chen, M., Cheng, F. (2012). A Novel Electrochemical Sensor for Formaldehyde Based on Palladium Nanowire Arrays Electrode in Alkaline Media. Electrochimica Acta, 68: 172-177.

[8] Yi, Q., Niu, F., Yu, W. (2011). Pd-Modified $\mathrm{TiO}_{2}$ Electrode for Electrochemical Oxidation of Hydrazine, Formaldehyde and Glucose. Thin Solid Films, 519: 3155-3161.

[9] Astuti Handayani, P., Abdullah, A., Hadiyanto, H. (2017). Biodiesel Production from Nyamplung (Calophyllum inophyllum) Oil Using Ionic Liquid as a Catalyst and Microwave Heating System. Bulletin of Chemical Reaction Engineering \& Catalysis, 12: 293298.

[10] Sivalingam, J.R., Kait, C.F., Wilfred, C.D. (2018). $\mathrm{CeO}_{2}-\mathrm{TiO}_{2}$ Photocatalyst: Ionic LiquidMediated Synthesis, Characterization, and Performance for Diisopropanolamine Visible Light Degradation. Bulletin of Chemical Reaction Engineering \& Catalysis, 13: 170-178.

[11] Buzzeo, M.C., Evans, R.G., Compton, R.G. (2004). Non-haloaluminate Room- Temperature Ionic Liquids in Electrochemistry-A Review. Chem Phys Chem, 5: 1106-1120.

[12] Nishi, N., Imakura, S., Kakiuchi, T. (2006). Wide Electrochemical Window at the Interface between Water and a Hydrophobic RoomTemperature Ionic Liquid of Tetrakis 3,5-
bis(Trifluoromethyl)phenyl]borate. Analytical Chemistry, 78: 2726-2731.

[13] Sun, W., Li, Y., Duan, Y., Jiao, K. (2009). Direct Electrochemistry of Guanosine on MultiWalled Carbon Nanotubes Modified Carbon Ionic Liquid Electrode. Electrochimica Acta, 54: 4105-4110.

[14] Lang, C.M., Kim, K., Guerra, L., Kohl, P.A. (2005). Cation Electrochemical Stability in Chloroaluminate Ionic Liquids. Journal of Physical Chemistry B, 109: 19454-19462.

[15] Zanoni, M.V.B., Rogers, E.I., Hardacre, C., Compton, R.G. (2010). The Electrochemical Reduction of the Purines Guanine and Adenine at Platinum Electrodes in Several Room Temperature Ionic Liquids. Analytical Chimica Acta, 659: 115-121.

[16] Liu, H.T., He, P., Li, Z.Y., Sun, C.Y., Shi, L.H., Liu, Y., Zhu, G.Y., Li, J.H. (2005). An Ionic Liquid-Type Carbon Paste Electrode and Its Polyoxometalate-Modified Properties. Electrochemistry Communications, 7: 13571363.

[17] Safavi, A., Maleki, N., Farjami, F., Farjami, E. (2009). Electrocatalytic Oxidation of Formaldehyde on Palladium Nanoparticles Electrodeposited on Carbon Ionic Liquid Composite Electrode. Journal of Electroanalytical Chemistry, 626: 75-79.

[18] Ensafi, A.A., Karimi-Maleh, H. (2010). Modified Multiwall Carbon Nanotubes Paste Electrode as a Sensor for Simultaneous Determination of 6-thioguanine and Folic Acid Using Ferrocenedicarboxylic Acid as a Mediator. Journal of Electroanalytical Chemistry, 640: 75-83.

[19] Beitollahi, H., Mazloum Ardakani, M., Ganjipour, B., Naeimi, H. (2008). Novel 2,2'-[1,2ethanediylbis(nitriloethylidyne)] -bis hydroquinone Double-wall Carbon Nanotube Paste Electrode for Simultaneous Determination of Epinephrine, Uric Acid and Folic Acid. Biosensors and Bioelectronics, 24: 362-368.

[20] Ensafi, A.A., Taei, M., Khayamian, T., Karimi-Maleh, H., Hasanpour, F. (2010). Voltammetric Measurement of Trace Amount of Glutathione Using Multiwall Carbon Nanotubes as a Sensor and Chlorpromazine as a Mediator. Journal Solid State Electrochemistry, 14: 1415-1423.

[21] Ensafi, A.A., Khoddami, E., Rezaei, B., Karimi-Maleh, H. (2010). p-AminophenolMultiwall Carbon Nanotubes- $\mathrm{TiO}_{2}$ Electrode as a Sensor for Simultaneous Determination of Penicillamine and Uric Acid. Colloids and Surfaces B Biointerfaces, 81: 42-49. 
[22] Wang, Z.H., Liu, J., Liang, Q.L., Wang, T.M., Luo, G. (2002). Carbon Nanotube-Modified Electrodes for the Simultaneous Determination of Dopamine and Ascorbic Acid. Analyst, 127: 653-657.

[23] Wang, J., Li, M., Shi, Z., Li, N. (2002). Direct Electrochemistry of Cytochrome $c$ at a Glassy Carbon Electrode Modified with Single-Wall Carbon Nanotubes. Analytical Chemistry, 74: 1993-1997.

[24] Rezaei, B., Damiri, S. (2008). Voltammetric Behavior of Multi-walled Carbon Nanotubes Modified Electrode-Hexacyanoferrate(II) Electrocatalyst System as a Sensor for Determination of Captopril. Sensors and Actuators B Chemical, 134: 324-331.

[25] Wang, J., Musameh, M. (2003). Carbon Nanotube/Teflon Composite Electrochemical Sensors and Biosensors. Analytical Chemistry, 75: 2075-2079.

[26] Ensafi, A.A., Karimi-Maleh, H. (2011). Voltammetric Determination of Isoproterenol Using Multiwall Carbon Nanotubes-Ionic Liquid Paste Electrode. Drug Testing and Analysis, 3: 325-330.

[27] Raoof, J.B., Ojani, R., Nadimi, S.R. (2004). Preparation of Polypyrrole/ferrocyanide Films Modified Carbon Paste Electrode and Its Application on the Electrocatalytic Determination of Ascorbic Acid. Electrochimica Acta, 49: 271-280.

[28] Feng, J.J., Zhao, G., Xu, J.J., Chen, H.Y. (2005). Direct Electrochemistry and Electrocatalysis of Heme Proteins Immobilized on Gold Nanoparticles Stabilized by Chitosan. Analytical Biochemistry, 342: 280-286.

[29] Samadi-Maybodi, A., Nejad-Darzi, S.K.H., Ganjali, M.R., Ilkhani, H. (2013). Application of Nickel Phosphate Nanoparticles and VSB-5 in the Modification of Carbon Paste Electrode for Electrocatalytic Oxidation of Methanol. Journal Solid State Electrochemistry, 17: 2043-2048.

[30] Alidusty, F., Nezamzadeh-Ejhieh, A. (2016). Considerable Decrease in Overvoltage of Electro-catalytic Oxidation of Methanol by Modification of Carbon Paste Electrode with Cobalt(II)-clinoptilolite Nanoparticles. International Journal of Hydrogen Energy, 41: 62886299.

[31] Đorđević, J.S., Maksimović, V.M., Gadžurić, S.B., Trtić-Petrović, T.M. (2017). Determination of Carbendazim by an Ionic Liquid Modified Carbon Paste Electrode. Analytical Letters, 50: 1075-1090.

[32] Koper, M.T.M., Hachkar, M., Beden, B. (1996). Investigation of the Oscillatory Electro-oxidation of Formaldehyde on $\mathrm{Pt}$ and $\mathrm{Rh}$
Electrodes by Cyclic Voltammetry, Impedance Spectroscopy and the Electrochemical Quartz Crystal Microbalance. Journal of the Chemical Society, Faraday Transactions, 92: 3975-3982.

[33] Stojanovic, A., Keppler, B.K. (2012). Ionic Liquids as Extracting Agents for Heavy Metals. Separation Science and Technology, 47: 189-203.

[34] Wegner, S., Janiak, C. (2017). Metal Nanoparticles in Ionic Liquids. Topics in Current Chemistry, 375: 65-87.

[35] Neouze, M.-A. (2010). About the Interactions between Nanoparticles and Imidazolium Moieties: Emergence of Original Hybrid Materials. Journal of Materials Chemistry, 20: 95939607.

[36] Yevidal A.D., Figlarz, M. (1987). Textural and Structural Studies on Nickel Hydroxide Electrodes. II. Turbostratic Nickel (II) Hydroxide Submitted to Electrochemical Redox Cycling. Journal of Applied Electrochemistry, 17: 589599.

[37] Raoof, J.B., Ojani, R., Abdi, S., Hosseini, S.R. (2012). Highly improved electrooxidation of formaldehyde on nickel/poly (otoluidine)/Triton X-100 film modified carbon nanotube paste electrode. International Journal of Hydrogen Energy, 37: 2137-2146.

[38] Bard, A.J., Faulkner, L.R. (2001). Electrochemical Methods: Fundamentals and Applications. Wiley-Interscience, New York.

[39] Azizi, S.N., Ghasemi, S., Yazdani-Sheldarrei, H. (2013). Synthesis of Mesoporous Silica (SBA-16) Nanoparticles Using Silica Extracted from Stem Cane Ash and Its Application in Electrocatalytic Oxidation of Methanol. International Journal of Hydrogen Energy, 38: 12774-12785.

[40] Laviron, E. (1979). General Expression of the Linear Potential Sweep Voltammogram in the Case of Diffusionless Electrochemical Systems. Journal of Electroanalytical Chemistry, 101: 19-28.

[41] Gosser, D.K.J. (1993). Cyclic VoltammetrySimulation and Analysis of Reaction Mechanism. (Wiley-VCH, New York, USA.

[42] Nicholson, R.S., Shain, I. (1964). Theory of Stationary Electrode Polarography. Single Scan and Cyclic Methods Applied to Reversible, Irreversible, and Kinetic Systems. Analytical Chemistry, 36: 706-723.

[43] Azizi, S.N., Ghasemi, S., Amiripour, F. (2016). Nickel/ P nanozeolite Modified Electrode: A New Sensor for the Detection of Formaldehyde. Sensors and Actuators B Chemical, 227: 1-10. 
[44] Hassaninejad-Darzi, S.K., Rahimnejad, M., Esfidvajani, M.G. (2016). Electrocatalytic Oxidation of Formaldehyde onto Carbon Paste Electrode Modified with Nickel Decorated Nanoporous Cobalt-Nickel Phosphate Molecular Sieve for Fuel Cell. Fuel Cells, 16: 89-99.

[45] Ojani, R., Raoof, J.B., Zavvarmahalleh, S.R.H. (2009). Preparation of Ni/poly (1, 5diaminonaphthalene)-Modified Carbon Paste Electrode; Application in Electrocatalytic Oxidation of Formaldehyde for Fuel Cells. Journal Solid State Electrochemistry, 13: 16051611.

[46] Raoof, J.B., Ojani, R., Abdi, S., Hosseini, S.R. (2012). Highly Improved Electrooxidation of Formaldehyde on Nickel/Poly (otoluidine)/Triton X-100 Film Modified Carbon Nanotube Paste Electrode. International Journal of Hydrogen Energy, 37: 2137-2146.

[47] Habibi, B., Delnavaz, N. (2010). Electrocatalytic Oxidation of Formic Acid and Formaldehyde on Platinum Nanoparticles Decorated Carbon-Ceramic Substrate. International Journal of Hydrogen Energy, 35: 8831-8840.

[48] Ojani, R., Raoof, J.B., Ahmady-Khanghah, Y., Safshekan, S. (2013). Copper-Poly (2aminodiphenylamine) Composite as Catalyst for Electrocatalytic Oxidation of Formaldehyde in Alkaline Media. International Journal of Hydrogen Energy, 38: 5457-5463.
[49] Korpan, Y.I., Gonchar, M.V., Sibirny, A.A., Martelet, C., Elskaya, A.V., Gibson, T.D., Soldatkin, A.P. (2000). Development of Highly Selective and Stable Potentiometric Sensors for Formaldehyde Determination. Biosensors and Bioelectronics, 15: 77-83.

[50] Demkiv, O., Smutok, O., Paryzhak, S., Gayda, G., Sultanor, Y., Guschin, D., Shkil, H., Schuhmann, W., Goncher, M. (2008). Reagentless Amperometric FormaldehydeSelective Biosensors Based on the Recombinant Yeast Formaldehyde Dehydrogenase. Talanta, 76: 837-846.

[51] Ben Ali, M., Gonchar, M., Gayda, G., Paryzhak, S., Maaref, M.A., JaffrezicRenault, N., Korpan, Y. (2007). Formaldehyde-Sensitive Sensor Based on Recombinant Formaldehyde Dehydrogenase Using Capacitance versus Voltage Measurements. Biosensors and Bioelectronics, 22: 2790-2795.

[52] Wang, Q., Zheng, J., Zhang, H., (2012). A Novel Formaldehyde Sensor Containing AgPd Alloy Nanoparticles Electrodeposited on an Ionic Liquid-Chitosan Composite Film. Journal of Electroanalytical Chemistry, 674: 1-6.

[53] Lyles, G.R., Dowling, F.B., Blanchard, V.J. (1965) Quantitative Determination of Formaldehyde in the Parts per Hundred Million Concentration Level. Journal of the Air Pollution Control Association, 15: 106-108. 